Article

\title{
Eco-Economic Coordination Analysis of the Yellow River Basin in China: Insights from Major Function-Oriented Zoning
}

\author{
Zhongwu Zhang ${ }^{1}$, Tianying Chang ${ }^{1}$, Xuning Qiao ${ }^{2,3, *}$, Yongju Yang ${ }^{2,3}$, Jing Guo ${ }^{2}$ and Han Zhang ${ }^{2}$ \\ 1 School of Geography, Shanxi Normal University, Linfen 041000, China; zhangzw@sxnu.edu.cn (Z.Z.); \\ changtianying0@hotmail.com (T.C.) \\ 2 School of Surveying and Land Information Engineering, Henan Polytechnic University, \\ Jiaozuo 454003, China; yjuz@hpu.edu.cn (Y.Y.); gguojing99@hotmail.com (J.G.); \\ zhang_hann@hotmail.com (H.Z.) \\ 3 Research Centre of Arable Land Protection and Urban-Rural High-Quality Development of Yellow River \\ Basin, Henan Polytechnic University, Jiaozuo 454003, China \\ * Correspondence: qiaoxuning@hpu.edu.cn
}

Citation: Zhang, Z.; Chang, T.; Qiao, X.; Yang, Y.; Guo, J.; Zhang, H.

Eco-Economic Coordination Analysis of the Yellow River Basin in China: Insights from Major

Function-Oriented Zoning.

Sustainability 2021, 13, 2715.

https://doi.org/10.3390/su13052715

Academic Editor: Antonio Boggia

Received: 18 January 2021

Accepted: 25 February 2021

Published: 3 March 2021

Publisher's Note: MDPI stays neutral with regard to jurisdictional claims in published maps and institutional affiliations.

Copyright: (C) 2021 by the authors. Licensee MDPI, Basel, Switzerland. This article is an open access article distributed under the terms and conditions of the Creative Commons Attribution (CC BY) license (https:/ / creativecommons.org/licenses/by/ $4.0 /)$.

\begin{abstract}
The ecological-economic coordination degree model is widely used to analyze eco-economic coordination relationships, but methods for determining the relative weights of the ecological and economic systems lack a scientific basis. Examining the Yellow River Basin based on Major FunctionOriented Zoning (MFOZ) in China, the study surveyed 42 experts and used the analytic hierarchy process (AHP)to calculate the ecological and economic weights of the different main function zones. It also improved the model and evaluated the coordination degree of the ecological economic system in 642counties of eight provinces in the Yellow River Basin from 1991 to 2015. The results indicate that (1) the ecological value of the basin increased from 823 billion Yuan in 2001 to 1142 billion Yuan in 2015; (2) the GDP shows a linear growth trend: high- and medium-high-value areas of per capita GDP are clustered around nine metropolitan areas, while cold spots are distributed in ecological protection and agricultural development zones; (3) the ecological and economic coordination of the river basin first rose and then declined; and (4) the coordinated development areas are concentrated in five urban agglomerations that are highly consistent with the per capita GDP hotspots.
\end{abstract}

Keywords: ecology and economy; coordination; sustainable development; Major Function-Oriented Zoning (MFOZ); analytic hierarchy process; Yellow River Basin

\section{Introduction}

The eco-environmental system is the basis for maintaining material circulation and biological survival, and economic development is the result of human use of natural and developed resources. With the rapid development of the economy and society, the contradictions between regional economic development, resource carrying capacity, and the ecological environment have become more prominent. The coordinated development of ecological environmental and economic systems has become an important basis for whether or not the region can achieve sustainable development [1]. In the 1660s, Petty linked the creation of economic value with the ecological environment for the first time. He believed that environmental factors, such as labor and land, can create value together. Since then, there have been similar studies on the coordinated development of the ecological environment and social economy, such as Malthus's population theory and Ricardo's theory of land rent. At present, the evaluation of the coordination relationship between the ecological environment and economic development is a hot topic in academic circles. Scholars have achieved diverse findings through large-scale research on the global $[2,3]$, country $[4,5]$, and province and city $[6,7]$ trends. Research at the small scale for a county, to comprehensively study its watershed, is insufficient. As a composite ecosystem, watersheds have received increasing attention due to the sensitivity of their ecological environment and diversity of scales [8]. 
In terms of evaluation methods, the first approach is to construct an ecologicaleconomic index system [9,10]; however, itis difficult to obtain data on the evaluation of county and smaller-scale units, the selection of indicators is very different, and the comparison of the measurement results is weak. The second is to construct a coupled evaluation model, including the Driving force-State-Response (DSR) model proposed by the United Nations Commission on Sustainable Development [11], the analytic hierarchy process (AHP) evaluation model [12], the ecological footprint evaluation model [13], and the coordinated development model $[14,15]$. The coordinated development degree model of the economy and environment has the widest application range;it avoids the difficulty of reflecting whether the overall regional ecological economic system is in high-level coordination or low-level coordination, and it can more objectively and clearly reflect the degree of interaction between the ecological environment system and the socio-economic system. The determination of the parameters in this model is subjective, and it is generally assumed that the ecological and economic systems are equally important. However, in reality, the effects of the ecological and economic systems in the different regions are not the same. To reflect this difference, to alleviate the contradiction between the ecological environment and economic development caused by urbanization and industrialization in China, and to promote the coordination and sustainability of economic development and ecological protection, the State Council of China-based on the regional resource and environmental carrying capacity, the existing development density, and development potential—approved and implemented the "National Plan for MFOZ" in 2010. The plan divides the land into optimized, key, restricted, and prohibited development areas according to development methods [16]. Major Function-Oriented Zoning (MFOZ) is a strategic, basic, and restrictive plan for China's land and space development;it is of great strategic significance to promote the formation of a land and space development pattern that is coordinated with the population, economy, resources, and environment, and to promote coordinated economic, social, and environmental development $[17,18]$. At the same time, it provides a new idea for the determination of model parameters; that is, based on the positioning of the main functions of different regions, the analytic hierarchy process is used to determine the weight of the economic and ecological systems.

The Yellow River Basin is an important economic zone and ecological barrier in China, and it plays a particularly important role in China's economic and social development and ecological security [19]. Due to the particular natural environment and geographic location, the economic and ecological environment of the Yellow River Basin is undergoing complex changes and is always facing severe challenges. Jin [20] and Xu et al. [21] put forward the idea of using regional classification guidance, coordinating and handling the "four major relationships", and promoting the ecological protection and high-quality development of the Yellow River Basin with the basic development pattern of "three regions and seven groups". However, they did not indicate how to coordinate the ecological-economic relationship between the different main function areas and how to achieve sustainable development. Related research has shown that GDP and GDP per capita can objectively reflect the levels of socio-economic development of a region, and are important indicators to measure the living standards of its people [22]. Among the ecological indicators, net primary productivity (NPP) is positively correlated with the supply and regulation functions of the ecosystem; its temporal and spatial changes track the changes in ecosystem functions [23,24], reflecting not only the ecosystem itself, but also the material, energy cycle, and change process [25], which can have important impacts on the natural environment. Therefore, the research is based on MFOZ, combined with coordination degree theory, to build an ecological-economic coordination degree model, with GDP, per capita GDP, and NPP as the economic and ecosystem indicators. The study quantitatively analyzes the ecological-economic system coordination degree of MFOZ for 642 counties in eight provinces of the Yellow River Basin from 1991 to 2015, and provides decision support for the ecological and economic coordination and sustainable development of MFOZ in the Yellow River Basin. 


\section{Research Area, Materials, and Methods}

\subsection{Research Area}

The river basin is located between $96^{\circ} \mathrm{E}-119^{\circ} \mathrm{E}$ and $32^{\circ} \mathrm{N}-42^{\circ} \mathrm{N}$; it is about $1900 \mathrm{~km}$ long from east to west and $1100 \mathrm{~km}$ wide from north to south, originating from the northern foot of the Bayan Har Mountains on the Qinghai-Tibet Plateau in China. The basin is vast, flowing through nine provinces, including Qinghai, Sichuan, Gansu, Ningxia, Inner Mongolia, Shaanxi, Shanxi, Henan, and Shandong, and finally into the Bohai Sea in Kenli County, Dongying City, Shandong Province (Figure 1). The drainage area is about $750,000 \mathrm{~km}^{2}$, with a total length of $5464 \mathrm{~km}$. It is the second-longest river in China and the fifth-longest river in the world. There are many mountains in the basin, and the height difference between east and west is huge, forming a three-level ladder from west to east, from high to low, which makes the natural conditions, such as geomorphology, climate, precipitation, and evaporation, of the different regions vary greatly. This region has an important position in China's economic development, with great growth potential and development space. As of 2018, the total population of the Yellow River Basin is 420 million, accounting for about $30.3 \%$ of the country, and the regional GDP is 23.9 trillion Yuan [26], or about $26.5 \%$ of the total. The basin is currently the area most strongly affected by the relationship between humans and land. In recent decades, rapid urbanization in some areas of the Yellow River Basin has led to an excessive load on the total amount of water used, and the water carrying capacity has been overloaded. The ecological environment has continued to deteriorate, restricting the sustainable development of the economy and society [27].

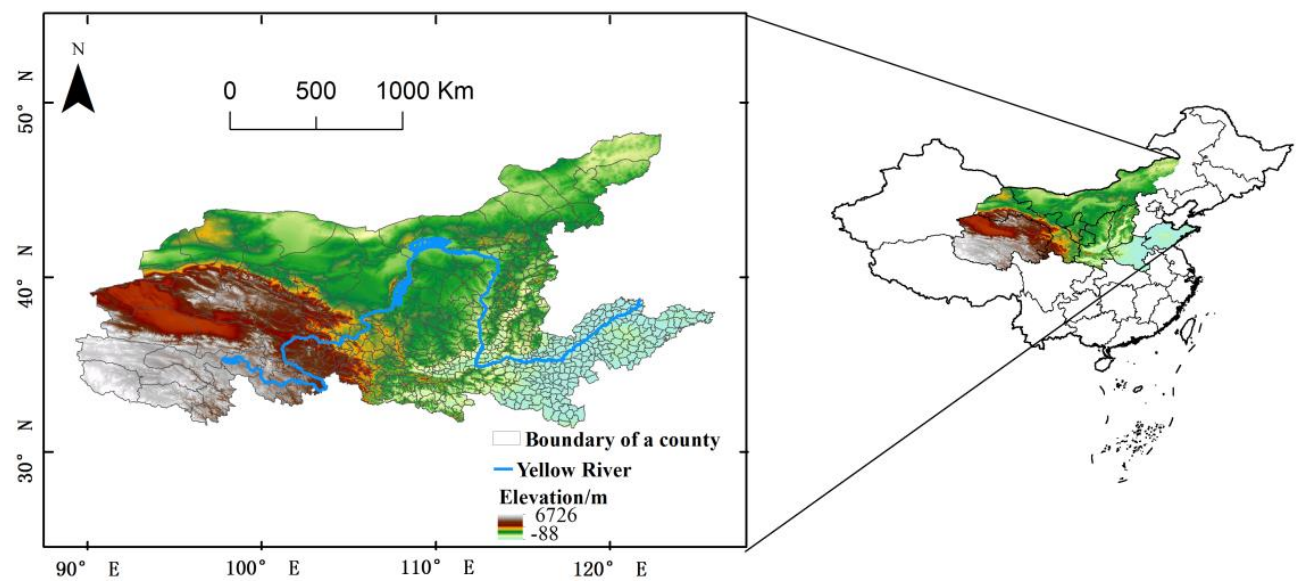

Figure 1. Location of the Yellow River Basin.

In September 2019, at the Symposium on Ecological Protection and High-Quality Development of the Yellow River Basin, this issue was upgraded to a major national strategy. Most of Sichuan Province is located in the Yangtze River Basin. Only Aba Tibetan and Qiang Autonomous Prefecture and Ganzi Tibetan Autonomous Prefecture flow through the Yellow River Basin; their population and economic total account for $0.7 \%$ and $0.3 \%$ of the Yellow River Basin, which has a weak influence on the economic and social development pattern of the Yellow River Basin. The eastern Inner Mongolia region has been included in the spatial scope of the "Northeast Region Revitalization Plan", and its economic and social development is closely related to the Northeast region. As the Yellow River Basin covers eight provinces, the study area in this article encompasses over 642 counties (cities, districts), including the upper reaches of Gansu, Ningxia, and Qinghai; the middle reaches of Inner Mongolia (excluding eastern Mongolia), Shaanxi, and Shanxi; and the lower reaches of Henan and Shandong. 


\subsection{Data Source and Preprocessing}

The 1991-2015 NPP data come from the monthly NPP of China's terrestrial ecosystems north of $18^{\circ} \mathrm{N}$ latitude $1 \mathrm{~km}$ raster dataset (1985-2015) (http:/ / www.geodoi.ac.cn/WebCn/ doi.aspx?ID=1212\&paperID=82fbe955-6d1a-42c9-afd3-af5c36b5863f\&tdsourcetag=s_pctim_ aiomsg). The spatial resolution is $1 \mathrm{~km}$, and the unit is $\mathrm{gC} /\left(\mathrm{m}^{2} \cdot \mathrm{a}\right)$. The image data for the NPP China region for 25 years (from 1991 to 2015) were obtained, which are based on the monthly meteorological data for China's land from 1985 to 2015, the soil texture data for China, and the land cover and vegetation index data products based on MODIS and AVHRR remote sensing images. The data were entered into the Carnegie-Ames-Stanford Approach (CASA) model and used to develop a1 km raster dataset of the monthly net primary productivity of China's terrestrial ecosystem north of the $18^{\circ} \mathrm{N}$ latitude for 31 years (1985-2015) [28,29]. In ArcGIS 10.2, the Yellow River Basin vector file was used to mask the abovementioned processed data to obtain the NPP data for 642 counties (cities, districts) in the eightprovinces ofthe Yellow River Basin from 1991 to 2015.

The GDP and GDP per capita of the counties (cities) in the Yellow River Basin are derived from the Statistical Yearbooks of the Provinces of the Yellow River Basin (1992-2016), the Yellow River Basin Yearbooks of the Provinces (1992-2016), the Statistics of Shandong Province and Qinghai Province Yearbook (1992-2016), and the Yearbook of Shandong Province and Qinghai Province (1992-2016). Among them, the GDP and per capita GDP indicators of some counties and cities are missing. Based on the data for adjacent years, interpolation and gray correlation forecasting methods were used to supplement them.

\subsection{Research Methods}

\subsubsection{NPP Change Trend Analysis Method}

The unary linear regression analysis method can be used to simulate the change trend of each raster pixel from 1991 to 2015, thereby reflecting the temporal and spatial evolution characteristics of the regional NPP. It is calculated as follows:

$$
\theta_{i}=\frac{n \times \sum_{i=1}^{n} i \times N P P_{i}-\sum_{i=1}^{n} i \sum_{i=1}^{n} N P P_{i}}{n \times \sum_{i=1}^{n} i^{2}-\left(\sum_{i=1}^{n} i\right)^{2}}
$$

where $\theta_{i}$ is the slope of NPP change over the years in the Yellow River Basin; $n$ is the number of years; $N P P_{i}$ is the average value of NPP in the $i$ th year; and $\theta_{i}>0$ indicates that NPP is increasing, and the opposite shows a decreasing trend. The absolute value of $\theta_{i}$ reflects the rate at which NPP increases or decreases.

\subsubsection{Ecological Value Evaluation}

The photosynthesis of vegetation is accompanied by the ecological process of the synthesis of organic matter essential for human survival and development, such as energy fixation, carbon sequestration, and oxygen production. The oxidation ratio of vegetation NPP will affect terrestrial carbon sinks [30]. To effectively and quantitatively evaluate the ecological effects produced in the process of NPP synthesis, using the estimation results of NPP, this paper expresses the ecological value in three parts: the value of organic matter production, the value of fixed $\mathrm{CO}_{2}$, and the value of $\mathrm{O}_{2}$ released. According to the photosynthesis equation, the mass ratio between primary productivity and $\mathrm{CO}_{2}$ and $\mathrm{O}_{2}$ is 100:163:120, and the mass of the three can be calculated. At the same time, the shadow price method is used to unify the three through price forms to obtain the ecological value calculation results [24].

1. The Value of Organic Matter

$$
N_{v}^{j}=\frac{N P P_{i}^{j}}{0.45} \times c
$$


In the formula, $N_{v}^{j}$ is the value of organic matter produced in the $j$ th year; $N P P_{i}^{j}$ is the average annual organic matter produced in the $j$ th year in the region; and 0.45 is the carbon content of NPP.

Considering that coal prices have been declining from 2012 to 2016, the closing price of Qinhuangdao $5500 \mathrm{kcal}$ thermal coal has dropped by about 100 Yuan/t per year, and the ecological value of coal prices during this period has a large deviation. Prices have stabilized since January 2017. In 2017, the annual average price of $5500 \mathrm{kcal}$ thermal coal was 611.7 Yuan/t (https:/ / www.cctd.com.cn/uploadfile/2018/0328/20180328093649264. pdf). The unit price converted into standard coal is $480.6 \mathrm{Yuan} / \mathrm{t}$, slightly higher than the 2010 standard coal unit price of 453.31 Yuan/t. Therefore, the study uses 480.6 Yuan/t as the unit price of standard coal to calculate the ecological value, and c is 480.6 Yuan/t.

2. Fixed $\mathrm{CO}_{2}$ Value and Release $\mathrm{O}_{2}$ Value

According to the photosynthesis equation, $\mathrm{CO}_{2}$ absorption and $\mathrm{O}_{2}$ emissions can be measured, and then the carbon tax method and the oxygen production cost method are used to measure their value [31]. The carbon tax conversion cost is $702.95 \mathrm{Yuan} / \mathrm{t}$, and the oxygen production cost is 400 Yuan/t [25].

3. Ecological Value

The value of organic matter produced, the value of fixed $\mathrm{CO}_{2}$, and the value of $\mathrm{O}_{2}$ released are integrated to obtain the ecological value of vegetation, $E_{v}^{j}$.

$$
E_{v}^{j}=N P P_{i}^{j} \times\left(\frac{c}{0.45}+702.95+400\right)
$$

\subsubsection{Analytic Hierarchy Process}

The analytic hierarchy process was proposed by Saaty of the United States; it treats complex decision-making issues as a system and decomposes it into multiple index levels to calculate the weight of each index level. The steps are as follows:

The matrix $\mathrm{A}$ is established according to the corresponding evaluation criteria and expert judgment, and the importance of $A_{i}$ and $A_{j}$ is determined according to the scale of Saaty1 9. According to Formula (4), one calculates the weight, $W^{A}$, of each indicator, where $\lambda_{\max }$ is the maximum eigenvalue of matrix $\mathrm{A}$.

$$
A W^{A}=\lambda_{\max } W^{A}
$$

Moreover, it is necessary to use $\mathrm{CR}$ to judge whether matrix A passes the consistency test. When $C R \leq 0.1$, it can be judged that the matrix passes the consistency test. The specific calculation is as in Formula (5), where $R I$ is the random consistency index.

$$
\mathrm{CR}=\frac{\left(\lambda_{\max }-\mathrm{n}\right) /(\mathrm{n}-1)}{R I}
$$

\subsubsection{Eco-Economic Coordination Evaluation}

As the two most important subsystems, the ecological economic system is tightly related to the natural environment and human living environment. Eco-economic coordination can measure the degree of harmony between the ecological and economic subsystems or the internal elements of the system [5]; it can represent the relationship between the natural environment and the human environment and measure the degree of harmony and synchronization between the two systems [22]. If the evaluation results of the two systems are synchronized, the region is in a coordinated state, and vice versa. The greater the dispersion is, the higher the degree of disorder is [25].

This study is based on MFOZ, and we selected GDP, per capita GDP, and NPP as the economic system indicators and ecosystem indicators to construct a model of ecologicaleconomy coordinated development. The MFOZ of the eight provinces in the Yellow River Basin divides the territorial space into four categories: optimized development zones, key 
development zones, restricted development zones, and prohibited development zones. Different types of territorial spaces have their own emphasis on ecological protection and economic development. The optimized development zone is an urbanized area where the economy is relatively developed, the population is dense, the development intensity is high, and resource and environmental problems are prominent. Industrialization and urbanization development should be optimized. Key development zones should improve their innovation capabilities, take a new path of industrialization and urbanization, and promote accelerated economic development to become an important growth pole supporting the future economic development of the Yellow River Basin and even the entire country. Restricted development zones are agricultural areas whose main function is to provide agricultural products and undertake important tasks in the construction of the national grain production core area, or areas with fragile ecosystems and low resource and environmental carrying capacity. The area should enhance comprehensive agricultural production capacity, and ecological products production capacity restricts the development of large-scale, high-intensity industrialization and urbanization. Prohibited development zones include representative natural ecosystems, natural concentrated distribution areas of rare animal and plant species, natural and cultural relics with special value, and other key ecological function areas. Compulsory protection shall be implemented, and human-made activities shall be strictly controlled. Various factors interfere with the natural ecology and improve environmental quality. In the evaluation of regional coordination relationships and model construction, different ecological and economic system weight values were set according to the main function positioning of the different regions in the Yellow River Basin.

According to the comprehensive evaluation results of the economic development level and ecological environment level of each region in the Yellow River Basin, and utilizing the concept of the dispersion coefficient, the ecological-economic coordination degree model was constructed to quantitatively evaluate the coordination of the economic development and ecological environment of the counties (cities) in the study area.

$$
C=\left\{\frac{d \times r}{\left[\frac{d+r}{2}\right]^{2}}\right\}^{\gamma}
$$

In the formula, $C$ is the degree of ecological-economic coordination; $d$ is the level of regional economic development-that is, GDP per capita; $r$ is the level of ecological environment-that is, the ecological value per unit area; and $\gamma$ is 2 , which is the adjustment coefficient [32]. The value range of $C$ is [0,1]; the larger the value of $C$, the smaller the dispersion between $d$ and $r$, and the more coordinated the regional economy and ecology, and vice versa.

To more fully reflect the degree of coordination of the ecological economy of the river basin, $C, d$, and $r$ are used to construct a coordinated development degree function:

$$
\begin{aligned}
& T=\alpha d+\beta r \\
& D=\sqrt{C \times T}
\end{aligned}
$$

In the formula, $T$ is the comprehensive evaluation index of ecological economy, reflecting the overall level of ecology and economy in the basin; $D$ is the coordinated development index of ecological economy, which is a comprehensive index for examining the degree of coordination and overall development of the basin's ecological economy; and $\alpha$ and $\beta$ are undetermined weights. The value range of $T$ is $(0,1)$; the larger the $T$, the higher the overall level of regional ecological environment and economic development. The value range of $D$ is $(0,1)$; the larger the $D$, the higher the coordinated development of the regional ecological economy. When the value range of $D$ is $(0,0.5)$, the regional ecological economy is in a stage of disordered development; when the value range of $D$ is $(0.5,0.6)$, it is in a 
weak coordination stage; when the value range of $D$ is $(0.6,1)$, it is in a stage of coordinated development.

According to the requirements of the MFOZ of the eight provinces in the Yellow River Basin, there are differences in the requirements for economic development and ecological protection in each type of development zone. Therefore, when calculating the comprehensive evaluation index of ecological economy and the coordinated development index of the Yellow River Basin, the values of $\alpha$ and $\beta$ mainly consider the requirements of different types of areas for economic development and ecological protection.

By issuing questionnaires to the 42 experts (these 42 experts came from universities and research institutes related to the basin, including the Chinese Academy of Sciences, East China Normal University, Henan Polytechnic University, Henan Institute of Geography, Henan University, Central China Normal University, Shanxi Normal University, Qinghai Normal University, Northwest Normal University, Sichuan Agricultural University, and so on. The male to female ratio was 2:1, with doctors accounting for $86 \%$, professors accounting for $36 \%$, and associate professors accounting for $42 \%$ ) participating in the MFOZ of the Yellow River Basin, the ecological and economic relative importance of the different major function zones in the upper, middle, and lower reaches of the Yellow River Basin were judged, the consistency was tested, and the geometric average was calculated. For the correlation weight matrix, the $\alpha$ and $\beta$ weight values were obtained by solving the eigenvector corresponding to the largest eigen root (Table 1). Since the prohibited development zones are mostly distributed in the form of points in the optimized, key, and restricted development zones (mainly distributed in the restricted development zones), the first three types of areas were considered in the study.

Table 1. Economic and ecological weights of the Major Function-Oriented Zoning (MFOZ) in the Yellow River Basin.

\begin{tabular}{ccc}
\hline ZoneType & $\alpha$ & $\beta$ \\
\hline Upstream key development zone & 0.59 & 0.41 \\
Upstream restricted development zone & 0.29 & 0.71 \\
Midstream key development zone & 0.77 & 0.23 \\
Middle restricted development zone & 0.41 & 0.59 \\
Downstream key development zone & 0.67 & 0.33 \\
Downstream restricted development zone & 0.37 & 0.63 \\
Downstream optimized development zone & 0.51 & 0.49 \\
\hline
\end{tabular}

Based on the main function types of different regions, $d$ and $r$ were calculated, and the regions were divided into three types: economic lag, synchronization, and ecological lag.

\section{The Spatio-Temporal Pattern of NPP in the Yellow River Basin}

\subsection{Temporal and Spatial Distribution Characteristics of Annual Average NPP of Vegetation}

From 1991 to 2015, the annual average NPP of the Yellow River Basin changed from 196 to $264 \mathrm{~g} \cdot \mathrm{m}^{-2} \cdot \mathrm{a}^{-1}$ (Figure 2), showing an increasing trend in fluctuations. The average value in 25 years was $224 \mathrm{~g} \cdot \mathrm{m}^{-2} \cdot \mathrm{a}^{-1}$. The annual average NPP was mainly concentrated between 100 and $300 \mathrm{~g} \cdot \mathrm{m}^{-2} \cdot \mathrm{a}^{-1}$, accounting for $55-83 \%$ of the study area, with an average of $70 \%$. The second is an NPP $<100 \mathrm{~g} \cdot \mathrm{m}^{-2} \cdot \mathrm{a}^{-1}$, accounting for the highest proportion of the total basin area in 2001 , reaching $27 \%$ with an average of $18 \%$. 


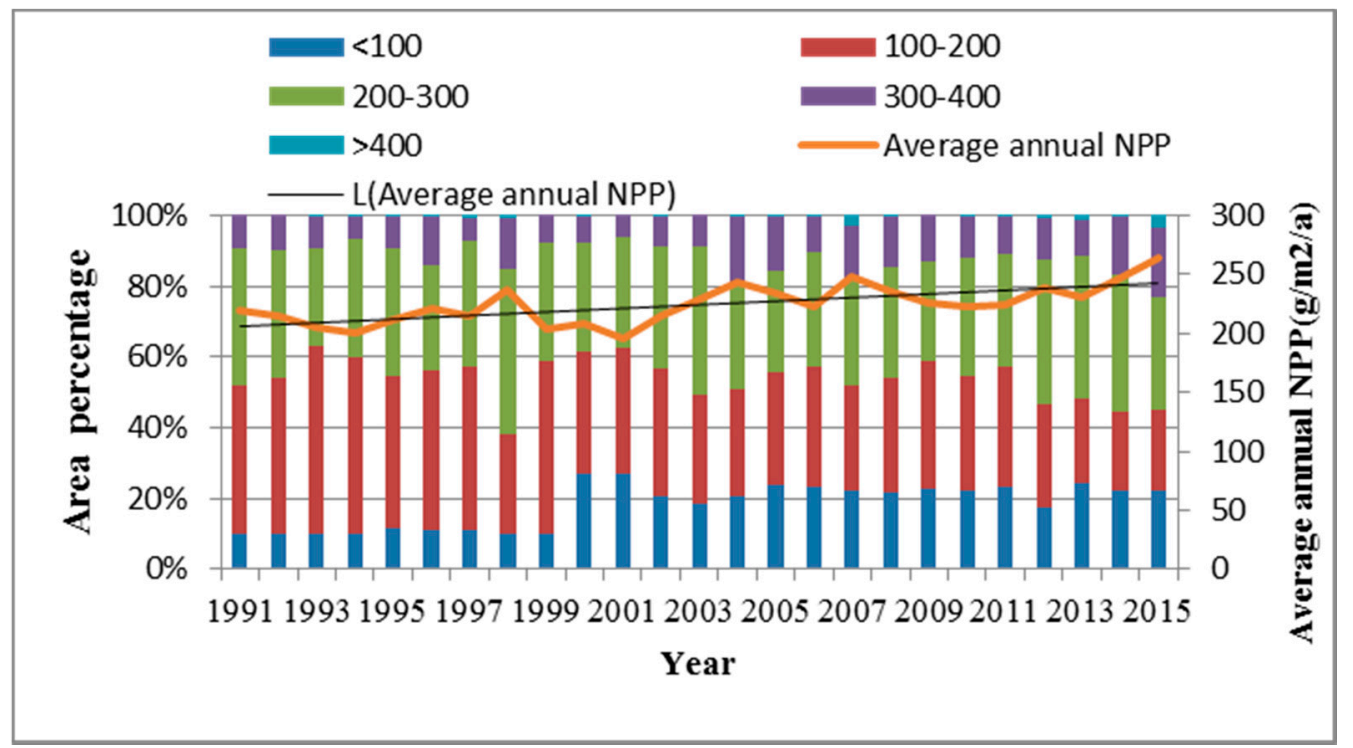

Figure 2. The inter-annual variation of the Yellow River Basin, 1991-2015.

From 1991 to 2015, the annual average NPP of the Yellow River Basin showed an overall spatial characteristic of high in the south and low in the north (Figure 3). The vegetation in the northwest of the study area has the lowest NPP, most of which is located in Inner Mongolia; this is because the northwest is a hilly and gully area on the Loess Plateau, with serious soil erosion, sparse vegetation, and poor ecological conditions. The highest NPP of the vegetation is located in the south; this is due to the high forest coverage in this area, and it is the main production area of agricultural products.
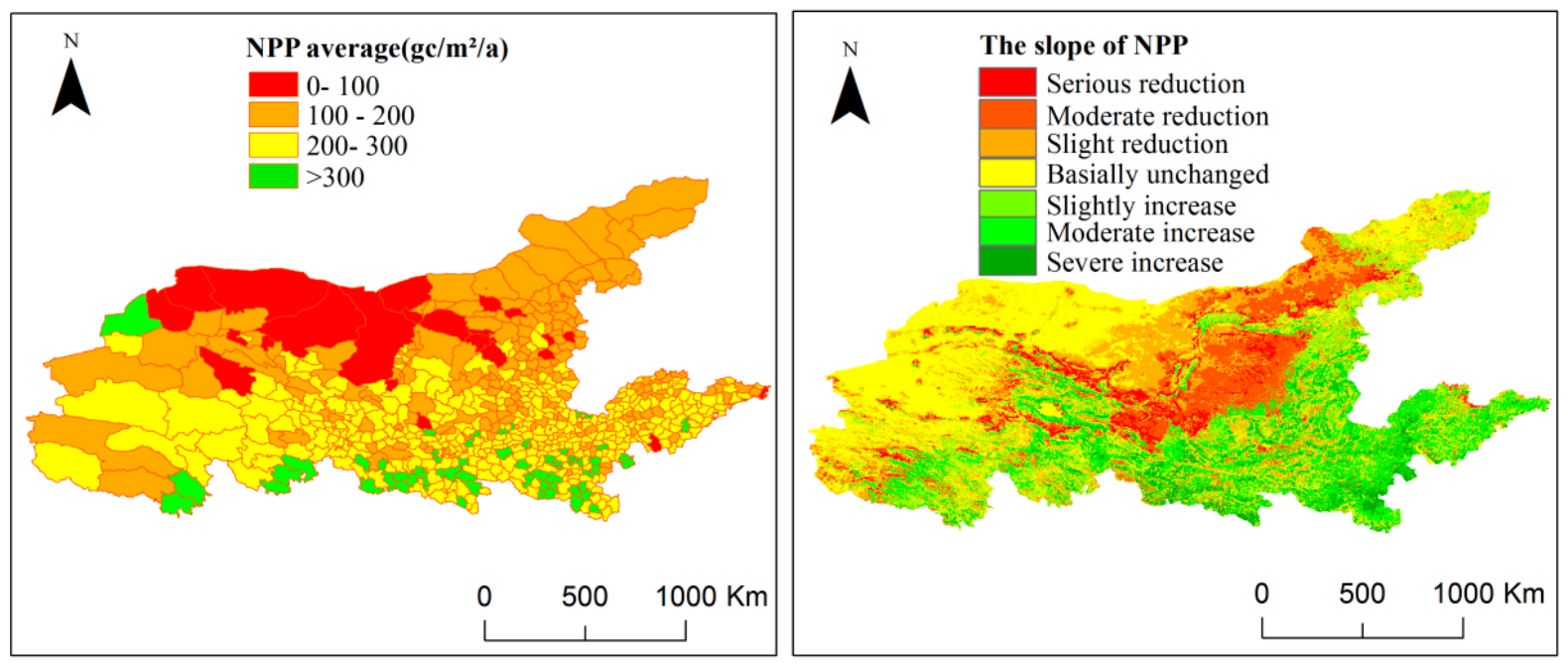

Figure 3. Distribution and slope of the net primary productivity (NPP) in the Yellow River Basin, 1991-2015.

\subsection{Analysis of the Change Trend inVegetation NPP}

Based on the pixel scale, the inter-annual change in vegetation NPP in the Yellow River Basin from 1991 to 2015 was analyzed by unary linear regression, the NPP change trend of each grid in the study area was obtained, and the results were reclassified by the natural discontinuity method (Figure 3). This can be roughly divided into seven categories: serious reduction, moderate reduction, slight reduction, basically unchanged, slight increase, moderate increase, and severe increase. The trend in vegetation NPPchange in the Yellow River Basin shows obvious regional spatial differences. Areas with slight and 
moderate reductions in NPP are mainly distributed in Ningxia, central Inner Mongolia, northern Shaanxi, and most municipal districts. This area is close to the Mu Us Desert, the Luliang Mountains, the coal resource-rich areas, and various urban agglomerations in the watershed. The ecological environment is extremely fragile, with low crop yields, high levels of industrialization and urbanization, and a harsh ecological environment. Areas with serious reductions in NPP are mainly distributed around the areas of slight and moderate reduction, which are distributed in dots and lines. The average annual NPP change slope is low, and the ecological environment is deteriorating. Areas with severe increases in NPP are mainly located in the "Two Rivers and One Water" ecological areas, such as Bailong River, Baishui River, West Hanshui River, Sichuan-Dianyun Forest Area, Hanzhong Basin, Fenhe River Valley Basin, and Huanghuaihai Plain, including Longnan City, Hanzhong City, Linfen City, Zhumadian City, Heze City, and other cities under the jurisdiction of the counties. The ecological environment in this area has been effectively protected, and the NPP is increasing annually. The areas with slight and moderate increases in NPP have a wide range, and those with close to a significant increase have expanded to the surrounding area, showing a trend in concentrated and contiguous distribution and indicating that the ecological environment of the Yellow River Basin is improving each year.

\section{Evaluation of the Ecological and Economic Coordination Relationship in the Yellow River Basin}

\subsection{The Dynamic Characteristics of Ecological Value and Economic Value in the Yellow River} Basin

To facilitate the analysis of the time-series characteristics of the ecological economy of the Yellow River Basin, the value of NPP in the Yellow River Basin from 1991 to 2015 was calculated based on the standard coal price of 480.6 Yuan/t. This studyused the general retail price index of the Yellow River Basin, and the GDP of the Yellow River Basin was revised to obtain the GDP data for the Yellow River Basin based on comparable prices in 2015.From 1991 to 2015, the ecological value of the Yellow River Basin showed an upward trend $\left(\mathrm{y}=0.586 \mathrm{x}^{2}-14.991 \mathrm{x}+1047.9, \mathrm{R}^{2}=0.178\right)$; the lowest value was 823 billion Yuan in 2001, and the highest was 1142 billion Yuan in 2015 (Figure 4). The GDP of the Yellow River Basin increased linearly $\left(y=62.757 x-308.36, R^{2}=0.8606\right)$, from 350 billion Yuan in 1991 to 15,160 billion Yuan in 2015-a 43-fold increase.

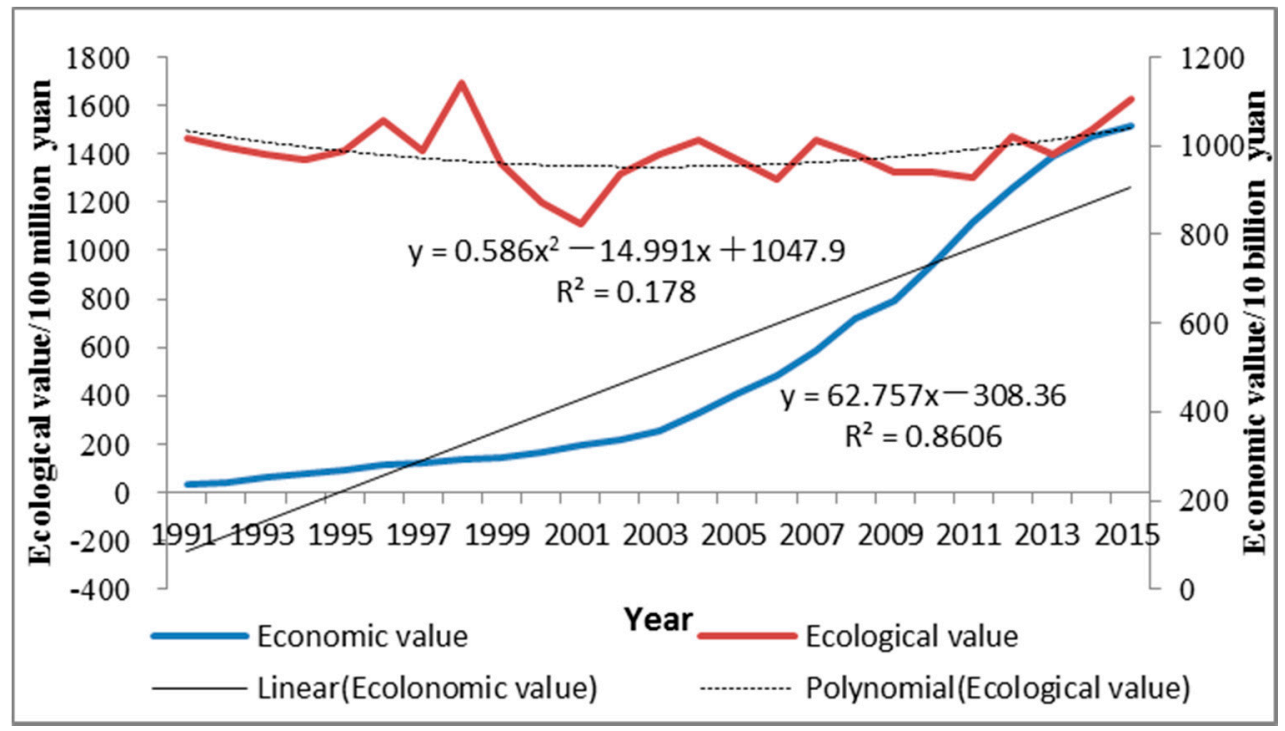

Figure 4. Dynamic changes of the NPP value and GDP of the Yellow River Basin, 1991-2015. 


\subsection{The Spatial Distribution Characteristics of Ecological Value in the Yellow River Basin}

Ecological value and ecological value per unit area are signs used to judge the quality of the regional ecological environment. The ecological value of the Yellow River Basin in 2015 was 1103 billion Yuan, accounting for approximately 7.28\% of the GDP in 2015.As can be seen from Table 2, Golmud City, Zhiduo County, Dulan County, Haixi Mongolian, the Tibetan Autonomous Prefecture, Maduo County, and five other cities and counties have the highest ecological value, with an average value of 33.94 billion Yuan; the ecological value of urban areas, such as Xuchang City District, Yima City, Jincheng City District, Linxia City, and Wulanchabu City District, is the lowest. The average ecological value per unit area of the Yellow River Basin in 2015 was 573,900 Yuan $/ \mathrm{km}^{2}$. The ecological value per unit area of five counties, including Pingdingshan City District, Mian County, Tanghe County, FangchengCounty, and JuCounty, ranks among the top five, with an average value of 983,200 Yuan $/ \mathrm{km}^{2}$. The average ecological value of five counties and cities, including Suzhou District, Ejina Banner, Yijinhuoluo Banner, Guyang County, and Yuanping City, is 61,900 Yuan $/ \mathrm{km}^{2}$, which is only one-tenth of the average for the basin. Combining the above two indicators, most counties have higher ecological values, while urban areas generally have lower ecological values.

Table 2. Ecological value of the eightprovinces in the Yellow River Basin in 2015.

\begin{tabular}{|c|c|c|c|c|}
\hline & Highest Valu & & Lowest Va & \\
\hline \multirow{5}{*}{$\begin{array}{l}\text { Ecological value } \\
\text { (100 million Yuan) }\end{array}$} & Golmud & 624.15 & Xuchang City District & 0.94 \\
\hline & Zhiduo County & 378.13 & Yima City & 0.88 \\
\hline & Dulan County & 289.41 & Jincheng City District & 0.87 \\
\hline & $\begin{array}{l}\text { Haixi Mongolian and Tibetan } \\
\text { Autonomous Prefecture }\end{array}$ & 205.86 & Linxia City & 0.70 \\
\hline & Maduo County & 199.21 & Ulanqab City District & 0.36 \\
\hline \multirow{5}{*}{$\begin{array}{l}\text { Ecological value per unit area } \\
\qquad\left(10,000 \text { Yuan } / \mathrm{km}^{2}\right)\end{array}$} & Pingdingshan City District & 99.08 & Suzhou District & 7.01 \\
\hline & Mian County & 98.75 & Ejina Banner & 6.34 \\
\hline & Tanghe County & 98.74 & Yijinhuoluo Banner & 6.30 \\
\hline & Fangcheng County & 97.74 & Guyang County & 6.23 \\
\hline & Ju County & 97.26 & Yuanping City & 5.07 \\
\hline
\end{tabular}

\subsection{The Spatial Characteristics of the Economic Development Level of the Yellow River Basin}

We used ARCGIS and natural clustering to divide the economic development of the Yellow River Basin in 2015 into five levels: high value, medium-high value, medium value, medium-low value, and low value (Figure 5). As a whole, values are low in the south and high in the north, and the lower reaches of the Yellow River Basin are higher than the upper and middle reaches.

In the upper reaches of the basin, contrary to NPP, areas with high and medium-high per capita GDP mainly appear in the Golmud and Jiuquan cities in the northwest. This area is a key development zone in Qinghai Province and Gansu Province, and a carrier of new industrialization and urbanization in the upper reaches of the Yellow River Basin. The low-medium and medium per capita GDP present a situation of overall dispersion and partial concentration. Areas with low per capita GDP are contiguously distributed, encompassing 95 counties and districts. These account for $32 \%$ of the entire low valuearea. This is mainly distributed in agricultural development areas, such as the Ningxia Plain Agricultural Area and the Liupan Mountain Forest Ecological Barrier Area, the Qinba Mountains, the Daliangshan Mountains, and other ecologically restricted development zones. Agriculture in this region is relatively developed and the ecological environment is 
good, but the industrial foundation is weak, the level of urbanization is low, and the urban economy is underdeveloped.
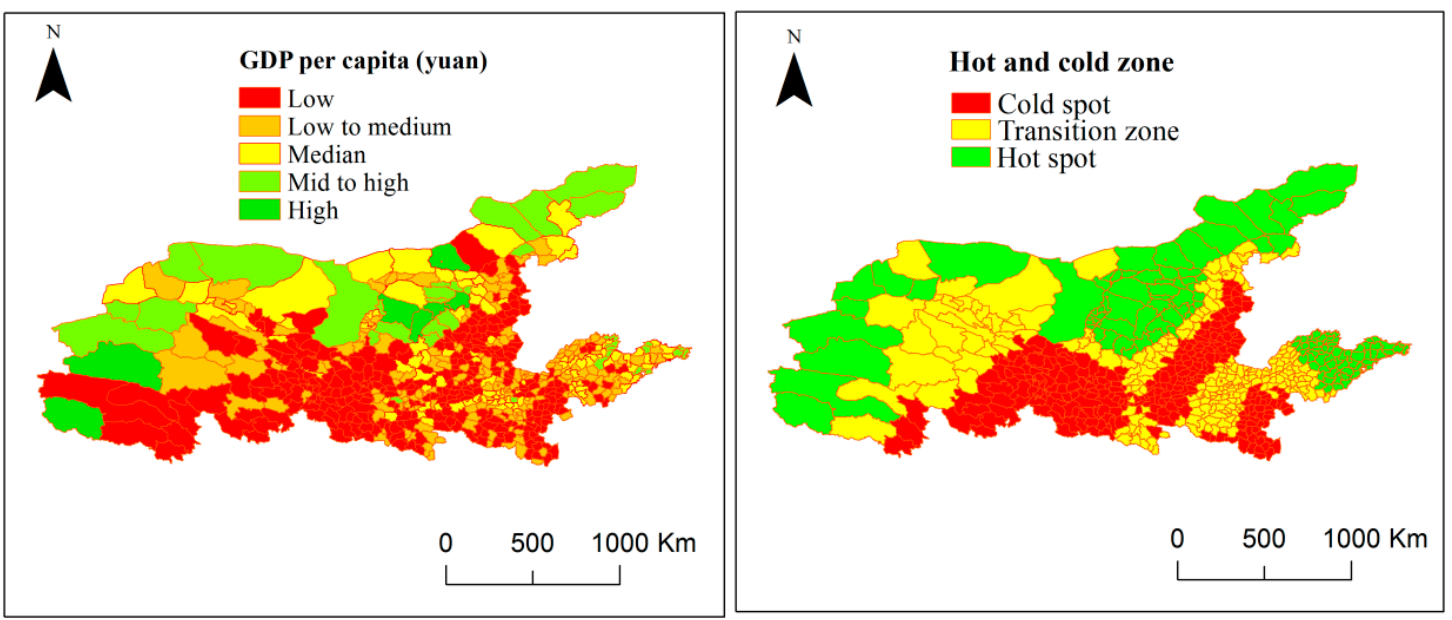

Figure 5. The spatial distribution of per capita GDP and the analysis of cold and hotspots of per capita GDP in the Yellow River Basin in 2015.

In the middle reaches, the high-value and medium-high-value areas of per capita GDP account for $58 \%$ of the entire study area. They are mainly distributed in restricted development zones, including Sunite Left Banner, Shenmu County, and Yulin City, and key development zones, including Zhungeer Banner, Tuoketuo County, Baotou City, and Wushen Banner. The low-medium and medium per capita GDP areas are dispersed but partially concentrated in Huanglong County, Fu County, Zhidan County, Xiangning County, $\mathrm{Pu}$ County, and Liangcheng County, among others. Areas with low per capita GDP are located in 123 counties, including Ningwu County, Lin County, Xi County, and Fangshan County. They are mainly distributed in mountainous areas in Shanxi, south of Helan Mountain and Qinling Mountain. This area is dominated by mountains, with complex terrain and inconvenient transportation, which is not conducive to high-quality economic development.

In the lower reaches, areas with high and medium-high per capita GDP are mainly located in 12 cities and counties, including Dongying City, Zibo City, Kenli County, Qingdao City, Weihai City, Zhengzhou City District, and others. This area is located in the optimized development zone and key development zone of the Yellow River Basin, mainly distributed on both sides of the Beijing-Guangzhou and Longhai railway lines. The diffusion and spillover effects of talent, capital, technology, and policies are obvious, and the transportation location advantage is prominent. The median GDP per capita area is mainly distributed within the boundary of the river basin, such as at the junction of Henan Province, Shanxi Province, and Shandong Province. This area is an ecological or agricultural area with relatively developed agriculture and a good ecological environment, but the urban economic development vitality is insufficient. There are a large number of lowmedium and low-value areas that are distributed contiguously, mainly in the agricultural areas of the Huanghuai Plain east of the Beijing-Guangzhou railway line.

The spatial agglomeration characteristics of the Yellow River Basin economy are analyzed using the cold- and hotspot analysis method [25]. The high-value areas and medium-high-value areas of per capita GDP are mainly concentrated in the nine metropolitan areas, with Jinan, Qingdao, and Zhengzhou in the lower Yellow River Basin and Xining, Lanzhou, Hohhot, Yinchuan, Xixian, and Taiyuan as the core (Figure 5). The high level of economic development has formed a hot area in the Basin, which has a significant role in driving the economic growth of the region. The cold-spot areas mainly have low per capita GDP, andare distributed in ecologically restricted development zones, such as Dingxi City and Baiyin City of Gansu Province along the Yellow River Agricultural Industrial Zone; 
Linfen City and Changzhi City of Shanxi Province City and other Fenwei plain agricultural areas; the TongbaiDabie Mountain ecological area is dominated by Gushi County and Shangcheng County in Henan Province; and the Huanghuai Plain area is dominated by Taikang County and Huaiyang County. The level of economic development in this region is low and agglomeration occurs, which has a negative effect on surrounding counties and cities. The transition area is located between the cold and hot areas, and the economic agglomeration effect is not significant.

\subsection{Degreeof Coordinated Development of an Ecological Economy in the Yellow River Basin}

\subsubsection{Time-Series Analysis}

The degree of ecological and economic coordination of the Yellow River Basin from 1991 to 2015 was calculated using Equations (6)-(8). The maximum value was 0.40 in 1997, and the minimum value was 0.22 in 2000 and 2009 (Figure 6). From 1991 to 2000, coordination rose and then fell, showing an "inverted U-shaped" trend. This indicates that the relationship between ecology and economy in the basin improved before 1997. The economic foundation in the basin is weak and development is slow, butit has not had a large negative impact on the environment. From 1997 to 2000, the relationship between ecology and economy in the basin became closer, and the degree of economic coordination in the basin dropped to the lowest level. From 2001 to 2009, coordination increased first and then declined. The relationship between ecology and economy in the basin is tense and antagonistic. After 2009, the relationship between the economy and environment tended to ease, and the degree of coordination between the two increased gradually.

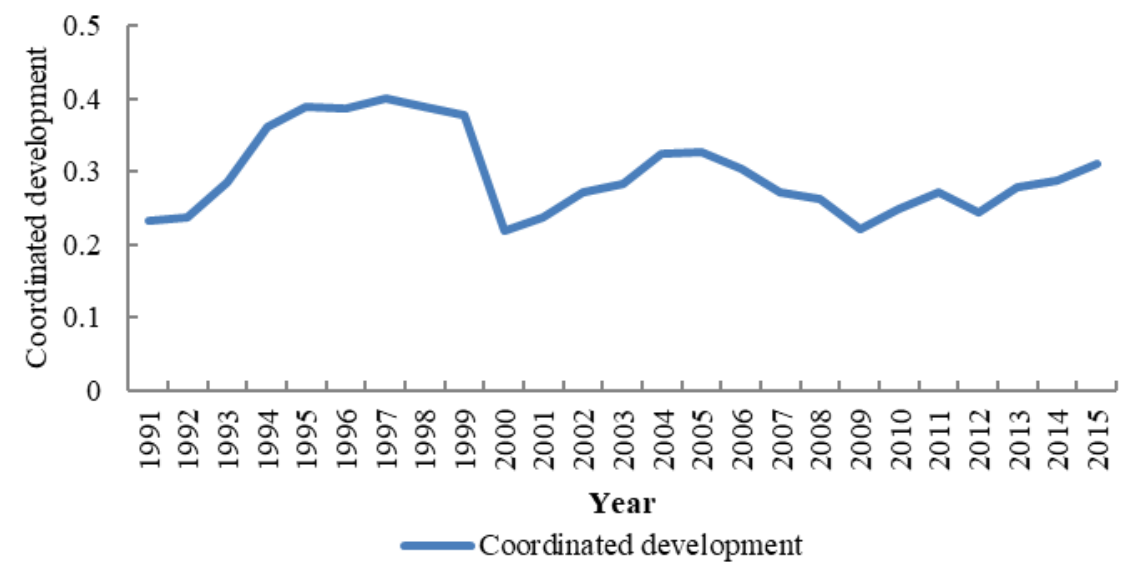

Figure 6. Coordinated development of the ecological economy in the Yellow River Basin, 1991-2015.

\subsubsection{Analysis of Spatio-Temporal Changes}

In 1991, 12 regions were in a state of coordinated development, 9were in a state of weakly coordinated development, and 621were in a state of disorder. In 2015, 41 regions were in a state of coordinated development, 50were in weakly coordinated development, and 551were in disorder (Figure 7). From 1991 to 2015, the coordination status of 96counties and cities changed. Of these, 84counties and cities improved, while 12declined. Among them, the coordinated development of ecological economy in the upper reaches of the Yellow River Basin has not changed much, and the middle and lower reaches were generally on the rise (Table 3). 


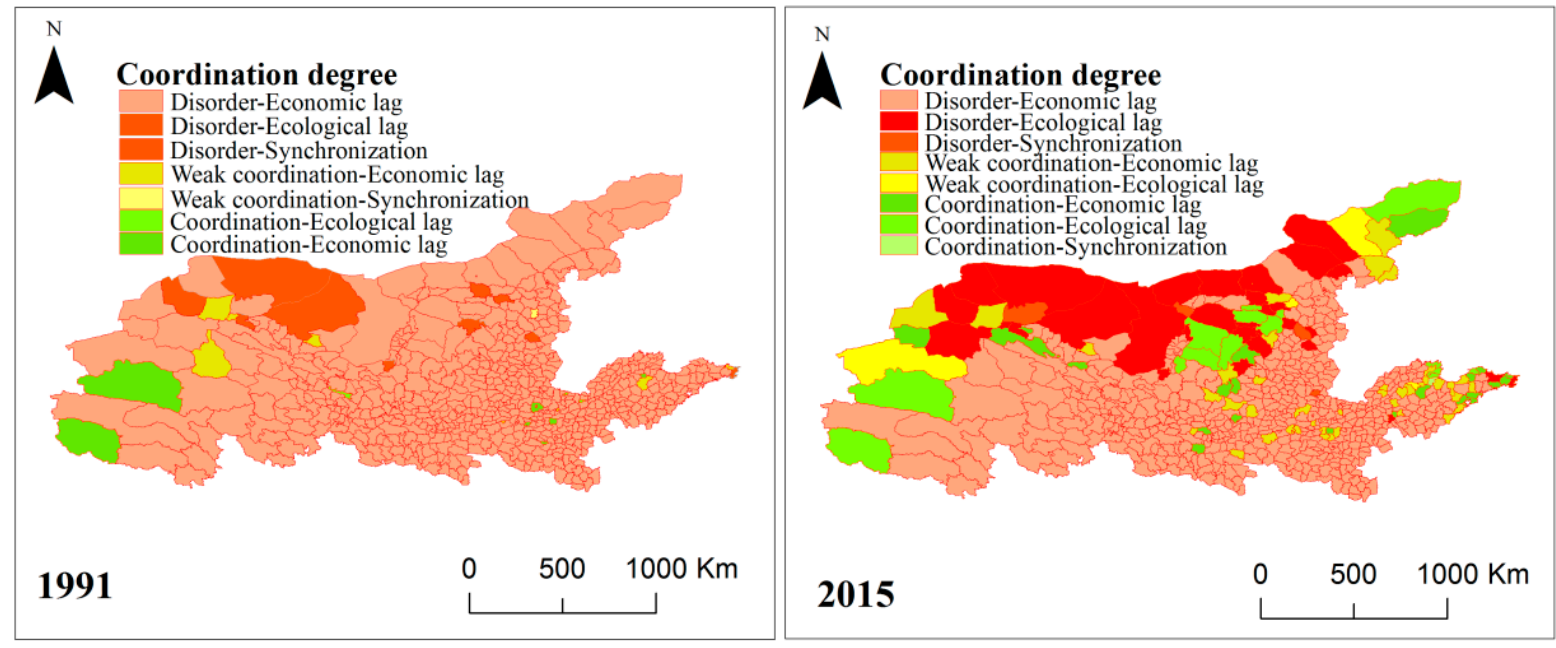

Figure 7. The distribution of coordinated development of the ecological economy in the Yellow River Basin, $1991-2015$.

Table 3. The coordinated development and changes in the Yellow River Basin from 1991 to 2015.

\begin{tabular}{cccccc}
\hline & Change State & Upstream & Midstream & Downstream & Total \\
\hline \multirow{4}{*}{ Rise } & Disorder-Weak coordination & 3 & 17 & 28 & 48 \\
& Disorder-Coordination & 6 & 15 & 13 & 34 \\
& Weak coordination-Coordination & 0 & 0 & 2 & 2 \\
\hline \multirow{3}{*}{ Fall } & Coordination-Disorder & 1 & 1 & 5 & 7 \\
& Coordination-Weak coordination & 0 & 0 & 0 & 0 \\
& Weak coordination-Disorder & 2 & 1 & 2 & 5 \\
\hline & Total & 12 & 34 & 50 & 96 \\
\hline
\end{tabular}

To further analyze these spatio-temporal evolution characteristics, this paper combines the coordination and synchronization of the regional ecological economy to divide the coordinated development of the ecological economy into disorder-economic lag, disordersynchronous development, and disorder-ecological lag; weak coordination-economic lag, weak coordination-synchronous development, and weak coordination-ecological lag; and coordination-economic lag, coordination-synchronous development, and coordinationecological lag. We calculated the coordinated development degree of 642 counties and cities in the Yellow River Basin in 1991 and 2015, and judged the coordinated development degree type (Figure 7). The number of counties, including the above types, in 1991 and 2015 were $612,2,8,8,1,0,8,0$, and 3, and 522, 4, 30, 42, 0, 4, 24, 1, and 15, respectively. From 1991 to 2015, the coordinated development of the ecological economy of the Yellow River Basin was dominated by disorder-economic lag, accounting for $81-95 \%$, and coordinated development was relatively low.

The coordinated development areas are mainly concentrated in the Shandong Peninsula urban agglomeration, with Jinan and Qingdao as the center; the Central Plains urban agglomeration, with Zhengzhou as the center; the Guanzhong Plain urban agglomeration, with $\mathrm{Xi}^{\prime}$ an as the center; the HubaoEyu urban agglomeration, with Hohhot as the center; andLanxi City Group, with Lanzhou City and Xining City as the center. The level of economic development has become the main factor affecting the coordinated development of the ecological economy. Weak coordination areas are scattered and close to the coordination areas, including economically developed regions, such as Zouping County, Abaga Banner, Hohhot City, Haixi Mongolian, and Tibetan Autonomous Prefecture; Duolun County, and Wuchuan County; Huachi County, Yumen County; and other economically underdeveloped areas. The economically developed regions have low NPP and poor ecological environment quality. The economic level of economically underdeveloped area is relatively low, the ecological value per unit area is high, and the ecological and economic 
systems are in weak coordination with a low degree of coordination. The disordered areas are vast, accounting for $86 \%$ of the Yellow River Basin. Most of the areas are located in the upper reaches of the Yellow River Ecological Restricted Development Zones and key energy-rich development zones in the middle reaches.

\section{Discussion}

\subsection{Comparison of NPP Data Accuracy in the Yellow River Basin}

Among the research objects, the NPP of vegetation in counties and districts under the jurisdiction of cities, such as Jiayuguan City, Delingha City, Xining City, and Haidong, $X_{i}$ 'an-Taiyuan Metropolitan Area, Dezhou, Binzhou, Dongying, and Weihai, is low. This is consistent with the fact that the urbanization level of the "one along nine tripods" metropolitan area and surrounding counties and cities in the nine provinces of the Yellow River Basin is relatively high and the vegetation coverage rate is low. The average NPP of the Yellow River Basin from 1991 to 2015 was $224 \mathrm{~g} \cdot \mathrm{m}^{-2} \cdot \mathrm{a}^{-1}$, and the variation range is $196-264 \mathrm{~g} \cdot \mathrm{m}^{-2} \cdot \mathrm{a}^{-1}$. This is consistent with the result that Tian et al. [33] calculated using MODIS17A3 data. The authors found that the average annual NPP of vegetation in the Yellow River Basin from 2000 to 2015 was $228.20 \mathrm{~g} \cdot \mathrm{m}^{-2} \cdot \mathrm{a}^{-1}$, and the range of variation was179.60-258.10 $\mathrm{g} \cdot \mathrm{m}^{-2} \cdot \mathrm{a}^{-1}$. Zhu [34] used the CASA model and the BP neural network model to dynamically simulate the vegetation NPP of the Yellow River Basin from 1992 to 2015 and found that the average annual NPP was $249.69 \mathrm{~g} \cdot \mathrm{m}^{-2} \cdot \mathrm{a}^{-1}$, which was close to the resultspresented in this paper:224 $\mathrm{g} \cdot \mathrm{m}^{-2} \cdot \mathrm{a}^{-1}$.

\subsection{Reliability Verification of Ecological-Economic Coordination Model}

This paper improves the ecological and economic coordinated development model of the Yellow River Basin based on MFOZ. To verify the findings, the following discussion is offered. First, the ecological and economic coordination degree of the Yellow River Basin, calculated here, shows the following trend: before 1997, the relationship between ecology and economy improved, and the coordination degree of the ecological economy gradually increased; from 1997 to 2009, the relationship between ecology and economy became closer, showing an antagonistic state; after 2009, the relationship between ecology and economy tended to ease, and the degree of ecological economy coordination gradually increased. Sun et al. [35] used the concept of inclusive green growth to build an economic and ecological coordinated development model to evaluate the green economic growth level of 285 cities in China from 2003 to 2015. They found that China's green economic growth level was low and relatively unstable before 2010; however, after 2010, the trend has been on the rise, which is consistent with the trend of ecological and economic coordination in the Yellow River Basin estimated in this study.

Second, in this study, the degree of economic and ecological coordination is between 0 and 0.6 , and the coordination degree is mainly disorder-economic lag. The coordination areas are mostly concentrated in key development zones with urban agglomeration as the core, while the disorder areas are mostly concentrated in agricultural development zones and ecologically restricted development zones in the middle and upper reaches of the Yellow River. From a regional perspective, Zameer et al. [36] established an eco-economic index system and a coupling coordination degree model and calculated that the economic and ecological coupling coordination degree of eastern, central, and western China from 2013 to 2018 was between 0.3 and 0.5 , which is still low. This demonstrates the pattern that the west is lower than the middle and the east, which is consistent with this article's findings.

Third, compared with traditional model, the improved model solved the problem of lacking scientific basis, but its precision will inevitably be affected by the subjectivity of the expert scoring and the number of experts. 


\subsection{Comparison of Research Results and Related Results}

On the whole, the coordination of ecological economy in the Yellow River Basin is low, which is consistent with the result that $\mathrm{Xu}$ et al. [26] found when they evaluated the nine provinces and regions in the Yellow River Basin from the two dimensions of high-quality economic development and ecological security.

From the perspective of the upper, middle, and lower reaches of the basin, the ecological and economic coordination of the Yellow River Basin presents the following pattern: downstream is higher than the middle reaches, and the middle reaches higher than the upper reaches (Figure 8). Shi [19] came to a similar conclusion when studying the coupling and coordination of ecological protection and high-quality economic development in the Yellow River Basin. Zhang [37] studied the high-quality development level of central cities in the Yellow River Basin from the five dimensions of economic structure, innovation-driven development, resource allocation, appropriate ecological livability, and sharing of public services. He concluded that the economic and social development of the Yellow River Basin showed a pattern of "upstream backwardness, midstream rising, and downstream development", which is roughly the same as the results of this paper.

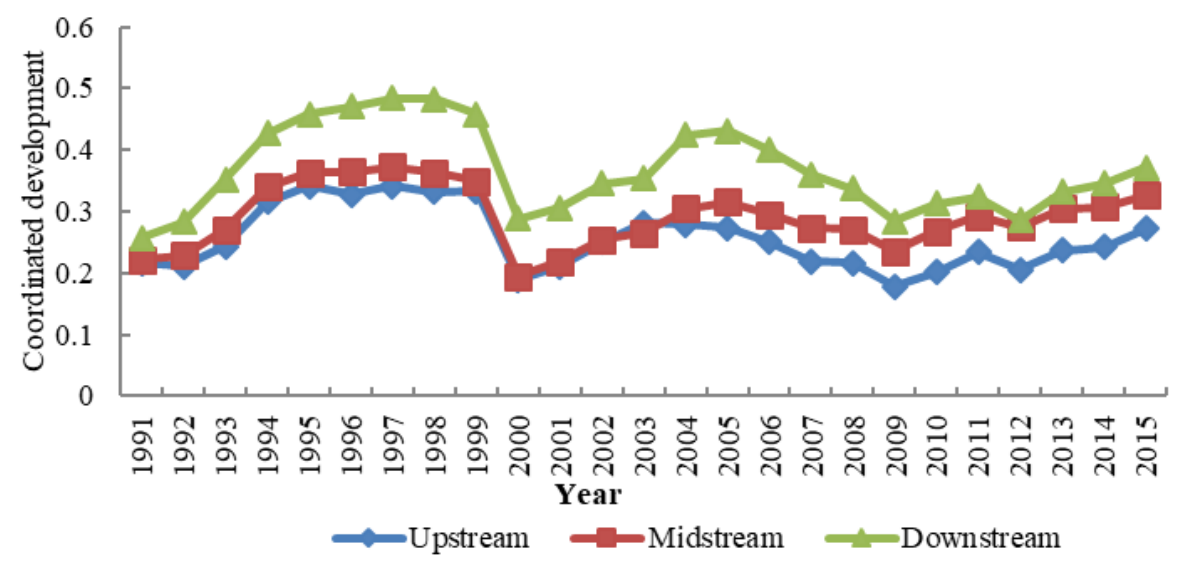

Figure 8. Degree of coordinated development of the ecological economy in the nine provinces (upper, middle, and lower reaches) of the Yellow River Basin, 1991-2015.

\subsection{Recommendationsfor Sustainable Development Policy of the Yellow River Basin Region}

Ecological protection and high-quality development of the Yellow River Basin, as a major national strategy, are important parts of regional coordinated and sustainable development. The economic and ecological coordination fluctuations of the Yellow River Basin are related to China's development strategies and policies in various periods. Since 2010, the "National Water Resources Comprehensive Plan (2010-2030)", the "Yellow River Basin Comprehensive Planning (2012-2030)", the "National Development Planning" issued by the State Council, the National Development and Reform Commission, and other government departments have all regarded the Yellow River Basin as a key area of economic ecology in China, thereby promoting the steady improvement of the economic and ecological coordination of the Yellow River Basin.

The degree of coordination of the upper and middle lower reaches of the Yellow River Basin was the closest in 1991, but the coordination degree of the lower reaches was higher than that of the upper and middle reaches later, which has a strongrelationship with the main function positioning of the upper and middle lower reaches. After 2004, the middle reaches were significantly higher than the lower reaches, which is closely related to the implementation of the policy of returning farmland to forest (grass) in the middle reaches of the Loess Plateau and the economic boost from energy development in the middle reaches of the Loess Plateau.

The territory upstream of the Yellow River Basin belongs to the national key limit development zone, and the inability to drive at the center of the city and urban agglom- 
eration has caused economic development to lag. Thus, policymakers should focus on thinking about river basin ecological compensation mechanisms, deepening the upgrades to western development policy, establishing a precise strategy for poverty alleviation in the west, improving the upstream area residents' income and welfare, and solving the problem of the up-stream's backward economy.

The middle reaches of the Yellow River Basin are mostly located in the Loess Plateau, where soil erosion is serious and the ecological environment is poor. The middle three provinces are also rich in coal resources. In the process of economic development, coal resources have been developed on a large scale. In addition, the unreasonable industrial structure and backward technical equipment of the three provinces have led to various ecological problems and accelerated the deterioration of the regional ecological environment. The ecological lag in the middle reaches of the Yellow River Basin requires thinking about continuing to deepen the policy of returning farmland to forest (grass), and using the new national strategy of ecological protection and high-quality development in the Yellow River Basin to properly resolve the contradiction between energy development and ecological protection in provinces such as Shanxi, Shaanxi, and Inner Mongolia.

Compared with the upper and middle reaches of the Yellow River Basin, the economic development level of the lower reaches of the Yellow River is higher, the ecological environment is better, and the degree of ecological and economic coordination is higher, but it is still lower than the national level. With the development of industrialization and urbanization, the contradiction between the attenuation of water resources and the rigid growth of water use in the lower reaches of the Yellow River Basin has become prominent, and the difficulty of ensuring agricultural water use has increased [20]. We should focus on improving the methods of ecological compensation, combining the ecological compensation mechanism of water resources with the compensation mechanism of cultivated land protection, and solving the problems of the unbalanced allocation of downstream water resources, food security, and farmers' income.

\section{Conclusions}

This paper improves the coordinated development model of ecological economy in the Yellow River Basin on the basis of main function areas, and considers the influence of different main function positions on the coordinated development of the ecological economy. It can be widely used in the analysis of the coordinated relationship between ecosystems and economic systems in different types of areas. The ecological and economic coordination of the Yellow River Basin has undergone three stages of change. From 1991 to 2000, coordination in the basin rose and then fell, presenting an "inverted U-shaped" trend. Before 1997, the relationship between ecology and economy in the basin tended to be better, and the economic foundation in the basin was weak and developed slowly, without significant negative impacts on the environment. From 1997 to 2000, the relationship between ecology and economy became increasingly close, and the coordination degree of economy in the basin decreased to the lowest level. From 2001 to 2009, ecological and economic coordination increased and then decreased. The coordination degree was very low, and the relationship between ecology and economy became closer. After 2009, coordination fluctuated upward. In the past 25 years, the coordinated development of ecological economy in the Yellow River Basin has been dominated by economic lagging imbalances, and the coordination of ecological economy presents the following pattern: downstream higher than midstream, and midstream higher than upstream. Generally speaking, the low level of economic development is the main factor for the imbalance of the ecological economy. The implementation of the "Develop the West" campaign plays an important role in improving western economic development and promoting the coordinated development of ecological economy. At the same time, the "Grain for Green" policy in the middle reaches has improved the service function of the ecosystem and promoted the coordinated development of the ecological economy. 
Research plays an important role in policy formulation for the Yellow River Basin. Based on the different main functions of the upper, middle, and lower reaches, corresponding countermeasures have been taken to solve the problem of coordinated development. The upstream areas should focus on solving the problem of upstream economic backwardness. The middle reaches should properly solve energy development and ecological development concerns. The downstream areas should mainly solve the problems of the unbalanced allocation of downstream water resources and low food security.

Author Contributions: Conceptualization, X.Q.; methodology, X.Q. and T.C.; software, T.C., Z.Z., J.G. and H.Z.; validation, J.G. and H.Z.; formal analysis, T.C., J.G., H.Z. and Z.Z.; investigation, T.C.; resources, Z.Z.; data curation, Z.Z., J.G. and T.C.; writing—original draft preparation, Z.Z., T.C. and X.Q.; writing—review and editing, Y.Y.; visualization, Y.Y., T.C.; supervision, Z.Z., X.Q.; project administration, Z.Z.; funding acquisition, X.Q. All authors have read and agreed to the published version of the manuscript.

Funding: This research was funded by the National Natural Science Foundation of China, grant number 41971274; the Philosophy and Social Science Scholar's Funds of Universities of Henan Province, grant number 2018-YXXZ-07; the Innovation research team of Henan Provincial University, grant number 2021-CXTD-08; theInnovation research team of Henan Polytechnic University, grant number CXTD2020-1.

Institutional Review Board Statement: Not Applicable.

Informed Consent Statement: Not Applicable.

Data Availability Statement: Not Applicable.

Acknowledgments: We express our gratitude to anonymous reviewers and editors for their professional comments and suggestions.

Conflicts of Interest: The authors declare no conflict of interest.

\section{References}

1. Harte, M.J. Ecology, sustainability, and environment as capital. Ecol. Econ. 1995, 15, 157-164. [CrossRef]

2. Pao, H.T.; Chen, H.P.; Li, Y.Y. Competitive dynamics of energy, environment, and economy in the US. Energy 2015, 89, 449-460. [CrossRef]

3. Ghosh, S.; Kanjilal, K. Long-term equilibrium relationship between urbanization, energy consumption and economic activity: Empirical evidence from India. Energy 2014, 66, 324-331. [CrossRef]

4. Chen, C.; Sun, Y.; Lan, Q.; Jiang, F. Impacts of industrial agglomeration on pollution and ecological efficiency: A spatial econometric analysis based on a big panel dataset of China's 259 cities. J. Clean. Prod. 2020, 258, 120721. [CrossRef]

5. Xu, M.Y.; Chen, C.T.; Deng, X.Y. Systematic analysis of the coordination degree of China's economy-ecological environment system and its influencing factor. Environ. Sci. Pollut. Res. 2019, 26, 29722-29735. [CrossRef]

6. Riao, D.; Zhu, X.; Tong, Z.; Zhang, J.; Wang, A. Study on land use/cover change and ecosystem services in Harbin, China. Sustainability 2020, 12, 6076. [CrossRef]

7. Sun, Y.; Cui, Y. Evaluating the coordinated development of economic, social and environmental benefits of urban public transportation infrastructure: Case study of four Chinese autonomous municipalities. Transp. Policy 2018, 66, 116-126. [CrossRef]

8. Wang, F.; Gao, C.; Hu, W. The influence of water transportation evolution on the economic development of cities along the Beijing-Hangzhou Grand Canal since the late Qing Dynasty. In Water-Related Urbanization and Locality: Protecting, Planning and Designing Urban Water Environments in a Sustainable Way; Wang, F., Prominski, M., Eds.; Springer Singapore: Singapore, 2020; pp. 27-45.

9. Zhao, Y.; Wang, S.; Zhou, C. Understanding the relation between urbanization and the eco-environment in China's Yangtze River Delta using an improved EKC model and coupling analysis. Sci. Total Environ. 2016, 571, 862-875. [CrossRef] [PubMed]

10. Wang, S.; Ma, H.; Zhao, Y. Exploring the relationship between urbanization and the eco-environment: A case study of BeijingTianjin-Hebei region. Ecol. Indic. 2014, 45, 171-183. [CrossRef]

11. Xie, J.; Ma, Y. Construction of carbon economy index system of Hebei Industry based on the model of DSR. In Proceedings of the 2014 4th International Conference on Education and Education Management, Hangzhou, China, 15-16 April 2017; Lee, G., Ed.; Information Engineering Research Institute: Texas City, TX, USA, 2014; Volume 68, pp. 224-227.

12. Zhang, D.; Yang, S.K.; Wang, Z.Z.; Yang, C.Y.; Chen, Y.Y. Assessment of ecological environment impact in highway construction activities with improved group AHP-FCE approach in China. Environ. Monit. Assess. 2020, 192, 451. [CrossRef]

13. Yang, Y.; Cai, Z. Ecological security assessment of the Guanzhong Plain urban agglomeration based on an adapted ecological footprint model. J. Clean. Prod. 2020, 260, 120973. [CrossRef] 
14. Yang, Y.; Bao, W.; Liu, Y. Coupling coordination analysis of rural production-living-ecological space in the Beijing-Tianjin-Hebei region. EcolInd 2020, 117, 106512. [CrossRef]

15. Han, H.B.; Zhong, Z.Q.; Guo, Y.; Xi, F.; Liu, S.L. Coupling and decoupling effects of agricultural carbon emissions in China and their driving factors. Environ. Sci. Pollut. Res. 2018, 25, 25280-25293. [CrossRef] [PubMed]

16. Fan, J. Draft of major function oriented zoning of China. Acta Geogr. Sin. 2015, 70, 186-201.

17. Fan, J. The strategy of major function oriented zoning and the optimization of territorial development patterns. Bull. Chin. Acad. Sci. 2013, 28, 193-206.

18. Fan, J.; Sun, W.; Zhou, K.; Chen, D. Major Function Oriented Zone: New method of spatial regulation for reshaping regional development pattern in China. Chin. Geogr. Sci. 2012, 22, 196-209. [CrossRef]

19. Shi, T. Spatial correlation network and regional connected effect of coupling coordination degree between ecological protection and high-quality economic development in the Yellow River regions. Reg. Econ. Rev. 2020, 3, 25-34.

20. Jin, F.J. Coordinated promotion strategy of ecological protection and high-quality development in the Yellow River Basin. Reform 2019, 11, 33-39.

21. Xu, Y.; Wang, C.S. Ecological protection and high-quality development in the Yellow River Basin: Framework, path, and countermeasure. Bull. Chin. Acad. Sci. 2020, 35, 875-883.

22. Giddings, B.; Hopwood, B.; O’Brien, G. Environment, economy and society: Fitting them together into sustainable development. Sustain. Dev. 2002, 10, 187-196. [CrossRef]

23. Carreño, L.; Frank, F.C.; Viglizzo, E.F. Tradeoffs between economic and ecosystem services in Argentina during 50 years of land-use change. Agric. Ecosyst. Environ. 2012, 154, 68-77. [CrossRef]

24. Richmond, A.; Kaufmann, R.K.; Myneni, R.B. Valuing ecosystem services: A shadow price for net primary production. Ecol. Econ. 2007, 64, 454-462. [CrossRef]

25. Qiao, X.N.; Wang, L.F.; Niu, H.P.; Yang, Y.L.; Gu, Y.Y. The eco-economic coordinate analysis of Huaihe River Basin in Henan Province based on NPPdata. Econ. Geogr. 2016, 36, 173-189.

26. Xu, H.; Shi, N.; Wu, L.L.; Zhang, D.W. High-quality development level and its spatiotemporal changes in the Yellow River Basin. Res. Sci. 2020, 42, 115-126. [CrossRef]

27. Kong, D.X.; Miao, C.Y.; Wu, J.W.; Borthwick, A.G.L.; Duan, Q.Y.; Zhang, X.M. Environmental impact assessments of the Xiaolangdi Reservoir on the most hyperconcentrated laden river, Yellow River, China. Environ. Sci. Pollut. Res. 2017, 24, 4337-4351. [CrossRef] [PubMed]

28. Chen, P.F. Monthly NPP Dataset Covering China's Terrestrial Ecosystems at North of $18^{\circ}$ N (1985-2015). J. Glob. Chang. Data Discov. 2019, 3, 34-41.

29. Chen, P.F. Monthly NPP 1 km Raster Dataset of China's Terrestrial Ecosystems (1985-2015). Glob. Chang. Res. Data Publ. Repos. 2019, 3, 34-41.

30. Randerson, J.T.; Masiello, C.A.; Still, C.J.; Rahn, T.; Poorter, H.; Field, C.B. Is carbon within the global terrestrial biosphere becoming more oxidized? Implications for trends in atmospheric $\mathrm{O}_{2}$. Glob. Chang. Biol. 2006, 12, 260-271. [CrossRef]

31. Zhenshan, W.; Shaoliang, Z.; Xuefei, W.; Yongjun, Y. Evaluation of environmental purification service for urban green space in Nanjing. Nat. Environ. Pollut. Technol. 2015, 14, 1019-1025.

32. Li, Y.; Li, Y.; Zhou, Y.; Shi, Y.; Zhu, X. Investigation of a coupling model of coordination between urbanization and the environment. J. Environ. Manag. 2012, 98, 127-133. [CrossRef]

33. Tian, Z.H.; Zhang, D.D.; He, X.H.; Guo, H.L.; Wei, H.T. Spatiotemporal variations in vegetation net primary productivity and their driving factors in Yellow River Basin from 2000 to 2015. Res. Soil Water Conserv. 2019, 26, 255-262.

34. Zhu, Y.Y. Remote Sensing Estimation of Vegetation Net Primary Productivity in the Yellow River Basin from 1992 to 2015 and Its Response to Climate Change. Ph.D. Thesis, Chang'an University, Xi'an, China, 2019.

35. Sun, Y.; Ding, W.; Yang, Z.; Yang, G.; Du, J. Measuring China's regional inclusive green growth. Sci. Total Environ. 2020, 713, 136367. [CrossRef] [PubMed]

36. Zameer, H.; Yasmeen, H.; Wang, R.; Tao, J.; Malik, M.N. An empirical investigation of the coordinated development of natural resources, financial development and ecological efficiency in China. Resour. Policy 2020, 65, 101580. [CrossRef]

37. Zhang, G.X.; Su, Z.X. Construction and measurement of high-quality development evaluation system for the central cities in the Yellow River Basin. Ecol. Econ. 2020, 36, 37-43. 